\title{
Bystanders in Bullying: Do ToM and Social Competence Skills Play a Role?
}

\author{
Panayiota Metallidou ${ }^{1}$, Magdalini Baxevani ${ }^{1} \&$ Grigoris Kiosseoglou $^{1}$ \\ ${ }^{1}$ School of Psychology, Aristotle University of Thessaloniki, Greece \\ Correspondence: Panayiota Metallidou, School of Psychology, Aristotle University of Thessaloniki, GR-541 24 \\ Thessaloniki, Greece. Tel: 30-2310-997-972; 30-2310-997-384.E-mail: pmetall@psy.auth.gr
}

Received: August 30, 2018 Accepted: September 7, 2018 Online Published: September 18, 2018

doi:10.5539/jedp.v8n2p174 URL: http://doi.org/10.5539/jedp.v8n2p174

\begin{abstract}
The present study aimed at investigating: (a) the direct effects of Theory of Mind (ToM) on elementary school children's self-reports of participant roles in school bullying, (b) ToM's indirect effects via self-reported social competence skills. Gender was examined as moderator. A total of 171 elementary school children ( $\mathrm{N}=95$ girls $)$ from $3^{\text {rd }}$ to $6^{\text {th }}$ grade from Greek public schools participated in the study. Participants were examined individually through the administration of advanced ToM stories. Also, they were asked to complete in groups self-report questionnaires as regards their roles as bystanders in bullying situations and their social competence skills. Path analysis indicated significant positive direct effects of ToM on prosocial skills and defending behavior and a negative effect on assisting/reinforcing behavior. Significant indirect effects were found from ToM on bystanding behavior, via its direct effect on prosocial competence skills. Gender was not a significant moderator of the above relations.
\end{abstract}

Keywords: bystanders in bullying, elementary school children, social competence, school bullying, theory of mind

\section{Introduction}

In the last two decades there is a growing research interest for one of the most pervasive forms of school violence, school bullying. Given the well-documented adverse consequences of bullying victimization in students' academic life, social functioning, and mental health, understanding its determinants in the school context is still a priority for teachers, parents and researchers. Bullying in the present study is defined as a proactive form of aggression which is characterized by imbalance of power and the bully's intention to repeatedly hurt physically and/or psychologically the victim (see Olweus, 1993). It involves traditional types of bullying (not cyberbullying), that are witnessed in school settings (e.g., hit, making laugh of, threat, tease or offend other kids). According to the evidence, school bullying occurs within a social context. This evidenced-based emphasis on the social nature of bullying has resulted in the adoption of a participant role approach and the consideration of bullying as a group process, a collective behavior (see Gini, 2006; Salmivalli, 2010; Salmivalli, Lagerspetz, Bjorkqvist, Osterman, \&Kankiainen, 1996; Sutton \& Smith, 1999). Children may take several roles in addition to bully and victim, by helping the bully (assistants), laughing and providing the bully with positive feedback (reinforcers), sticking up for the victim (defenders) or remaining uninvolved and, thus, silently approve bullying (outsiders) (see also Gini, Albiero, Benelli, \&Altoe, 2008). Research evidence has shown 'moderate' stability in the roles children adopt over time, implying that they may adopt multiple participant roles at the same time, depending on personal and situational factors (see Maunder \& Crafter, 2018). Why someone chooses to defend a victim or to withdraw and stay silent in a bullying situation is still a puzzling question. The examination of motives, cognitions, and other personal characteristics of bystanders has recently attracted research interest, in an attempt to understand the dynamics in bullying as a group-based phenomenon (Forsberg, Thornberg, \& Samuelsson, 2014; Pronk, Goossens, Olthof, De Mey, \&Willemen, 2013; Van der Ploeg, Kretschmer, Salmivali, \&Veenstra, 2017). Bystanders (e.g. reinforcers vs defenders) 'matter', as have been found to predict the frequency of bullying incidents in elementary classrooms and, thus, should be the target of interventions as well (Salmivali, Voeten, \&Poskiparta, 2011). Almost $24-30 \%$ of children have been found not to take side or to withdraw from bullying incidents (see Salmivali, 2010 for a review). Research, though, is still limited as regards their cognitions, skills, and motives (e.g., Pronk et al., 2013), as most of the studies have examined the individual and contextual predictors for the three main groups of 
children and adolescents in bullying, namely bullies, victims, and bully victims (see for meta-analysis Cook, Williams, Guerra, Kim, \&Sadek, 2010).

The present study is an investigation of the role of Theory of Mind (ToM) and different aspects of social competence skills and behaviors (prosocial vs antisocial) as predictors of elementary students' self-reports of acting as bystanders in bullying situations. Given the social nature of bullying, ToM and social competence skills are two socio-cognitive constructs that are theoretically linked to bullying-related behaviors. The role of ToM in bullying is still a controversial issue and the existing evidence for bystanders (assistants, reinforcers, defenders and outsiders) is very limited (for a review see Smith, 2017). In regards to the role of social skills in bullying, most of the studies have focused on the predictive role of empathy as the most closely related prosocial factor to bullying-related behaviors (see Mitsopoulou\&Giovazolias, 2015; van Noorden, Haselager, Cillessen, \& Bukowski, 2015), while antisocial aspects of behavior are understudied. Further, it is understudied the mediated role of various prosocial and antisocial factors in the relation between ToM and participant roles in bullying. Empirical evidence will be presented as regards the predictive role of ToM and various social competence skills for different participant roles in bullying situations.

\subsection{Theory of Mind and Bystanders in Bullying Situations}

Theory of Mind (ToM) refers to a person's ability to attribute mental states (e.g., beliefs, desires, and intentions) to oneself and others and, thus, to predict and explain behavior. Research on ToM has traditionally focused on preschool-aged children (e.g., Wellman, Cross, \& Watson, 2001) or early school-aged children (e.g., Miller, 2009) and has shown that it is a well-documented accomplishment of early childhood. Further, ToM has been examined as a central aspect of social cognition, since the ability to represent mental states has been found to play a vital role in one's interactions with others (e.g., Sutton, Smith, \&Swettenham, 1999). High ability, however, to 'read the mind' implies not only the presence of empathy skills, especially cognitive empathy, but also of pretend and deception skills.

A related controversial issue is whether children who take active role in bullying situations, especially those who are leaders, can effectively read others' minds or not (see contradictive evidence in Caravita Di Blasio, \&Salmivali, 2010; Gini, 2006; Sutton et al., 1999 vs Barlow, Qualter, \& Styllianou, 2010; Baxevani \& Metallidou, 2015; Shakoor, Jaffee, Bowes, Ouellet-Morin, Andreou, Happe, et al., 2012). The picture is even more complex, since various factors have been found to intervene and affect the relation between ToM and participant roles in bullying, such as the type of ToM tasks, the type of aggression, age, and gender (for a review see Smith, 2017). Further, there is inconsistent evidence as regards the moderating role of various types of social competence skills, such as empathy, in the relation between ToM and bullying and/or aggressive behavior (see Bjorqkvist, Osterman, \&Kaukiainen, 2000 vs Caravita et al., 2010) in elementary school children.

In regards to the relation between ToM and bystanders in bullying situations, there is limited empirical evidence. According to a recent review, only nine studies have examined the relation between ToM and bullying and only four of these reported evidence for bystanders, mainly for defenders (see Smith, 2017). Specifically, Sutton et al. (1999b) in their initial study with children from 7 to 10 years old found that bullies scored higher in ToM tasks from assistants and reinforcers, even from defenders, challenging, thus, Crick and Dodge's (1994) claim for a 'social skills deficit' of aggressive children and starting the discussion about the high 'reading of mind' abilities of bullies. They found, however, zero correlations between performance on ToM tasks and defenders. These results were not confirmed by Gini (2006) in a sample of 8-11 years children. In fact, Gini (2006) found the opposite, that is, defenders scored highest as compared to victims and bullies in all ToM tasks. Positive associations between defenders and ToM were found also in a sample of Italian students from 9 to 11 years, especially for boys who scored high in prosocial skills (affective empathy and social preference) (see Caravita et al., 2010). In general, however, interactions with gender either not reported or are not significant. Further, the associations between ToM and assistants and reinforcers were found to be weak or non-significant (see Smith, 2017).

\subsection{Social Competence and Bystanders in Bullying Situations}

A core element of social competence is the person's ability to effectively interact with others by organizing her/his own personal and environmental resources (see Junttila, Voeten, Kaukiainen, \&Vauras, 2006). At the behavioral level, social competence means that there is both the manifestation of prosocial behavior (e.g., helping, cooperating, and comforting) and the absence of antisocial behavior (e.g., impulsive and disruptive behavior). Empathy has been studied as the most closely related pro-social factor to bullying-related behaviors (e.g., Caravita et al., 2010; Jolliffe \& Farrington, 2011; Mitsopoulou \& Giovazolias, 2015; Stavrinides, Georgiou, \&Theofanous, 2010; van Noorden et al., 2015). The correlations between bullying and empathy remain stable during middle childhood through adolescents (see meta-analysis Mitsopoulou \& Giovazolias, 2015). It is noteworthy that, 
according to recent evidence from elementary school children, only affective (and not cognitive empathy) is a significant predictor of defending behavior over time and defenders are rewarded with increased popularity (van der Ploeg et al., 2017). In general, defenders are social competent children, characterized by high levels of affective empathy, low levels of rejection by classmates, high popularity, and high morality (Camodeca, Caravita, \& Coppola, 2015; Caravita, Di Basio, \&Salmivali, 2009; Pozzoli, Gini, \&Thornberg, 2016; Salmivali et al., 1996).

Research evidence is either limited or less clear, though, in regards to the relation between social competence skills and different groups of bystanders. While defenders present a well-documented prosocial profile, research evidence concerning outsiders' social competence profile is unclear. There is evidence indicated either no significant differences between defenders and outsiders in various aspects of social cognitions (e.g., self-efficacy of assertion, expectations that aggression lead to rewards, value of victim suffering) in elementary school children (Andreou \& Metallidou, 2004) or low levels of social self-efficacy only in outsiders' behavior (e.g., Gini et al., 2008). Outsiders were found to have low social status and popularity among their peers, as if they are 'invisible' for their peers (Caravita et al., 2009, 2010).

\subsection{The Rationale of the Present Study}

The present study is part of a larger research project under the supervision of the first author, which aimed at examining the socio-cognitive profile of elementary students who adopt different participant roles in school bullying, based on their self-reports. The aim here is to investigate the direct and indirect (via social competence) effects of ToM on elementary students' self-reports of acting as bystanders in bullying situations. Specifically, the present study aimed at examining whether: (a) performance on ToM tasks and self-reported prosocial and antisocial behavior are significant direct predictors of students' self-reports of acting as bystanders in bullying situations, (b) ToM affect not only directly but indirectly the by-standing behavior via its direct effects on the social competence factors, and (c) gender act as a significant moderator of the above effects.

The direct effects of ToM and social competence are expected to be differentiated according to the type of by-standing behavior. Based on previous evidence, self-reports of acting as defender would be positively predicted by performance on ToM tasks (Hypothesis 1a) (see also Caravita et al., 2010; Gini, 2006), affective empathy (Hypothesis 1b) (van der Ploeg et al., 2017), and cooperative skills, based on the evidence showing high social status and popularity for defenders (Hypothesis 1c). No clear hypothesis can be formulated for the effects of ToM and social competence on reinforcing, assisting, and uninvolved behavior, given the lack of evidence and the weak or non-significant associations that have been found.

In regards to the relations of ToM with social competence, ToM development beyond preschool years has been found to have positive, negative or neutral effects on social relations (for a review see Hughes \& Leekam, 2004). Longitudinal evidence from preschool and early elementary school children indicate bidirectional complex associations between peer relations and social cognition. Difficulties in social cognition found to predict increased peer rejection among children in middle childhood (Banerjee, Watling, \& Caputi, 2011). Further, indirect paths were found from early theory of mind to subsequently lower peer rejection and higher peer acceptance, via improvements in prosocial behavior in the transition from preschool to elementary years (Caputi, Lecce, Pagnin, \& Banerjee, 2012). Recently Devy, White, Ensor \& Hughes (2016) found in middle childhood concurrent longitudinal correlations between students' ToM and teachers' ratings for students' social competence in school. ToM found to predict later social competence. Based on the above evidence, positive direct effects of ToM on cooperation skills and empathy are expected (Hypothesis 2). The impact of ToM on aspects of anti-social behavior (disruptive behavior and quick temperedness) is still an open question.

Finally, gender is expected to have a differentiated impact on the effects of ToM and social competence on the bystanding roles, depending of the specific participant role and the specific aspect of social competence (Hypothesis 3). More girls have been found among the defenders while more boys among the reinforcers and followers (see Anderou \& Metallidou, 2004; Salmivalli et al., 1996). Further, gender has been found as a significant moderator of the relation between roles in bullying and empathy. Namely, girls found to report higher levels of empathy than boys in general, while high levels of empathy were found to be related to defending behavior only in boys (Caravita et al., 2009, 2010). Also, only the aggressive girls and not boys have been found to report low levels of empathy (Warden \& MacKinnon, 2003). Significant interactions, though, between ToM, bystanding behavior and gender either not reported or are not significant (see Smith, 2017).

\section{Method}

\subsection{Participants}

One hundred and seventy one Greek elementary students of both genders ( $\mathrm{n}=95$ girls), from the end of third grade 
to the beginning of six grade ( $M=120.7$ months, $S D=12.31)$ were examined individually and in groups. Students came from different public elementary schools located in the city of Thessaloniki, the second largest city in Greece, and one school from a smaller city, in order to collect data from different educational environments and socioeconomic regions (West, East and Center city areas).

\subsection{Measures}

Cognitive tasks and self-report questionnaires were used to measure all the variables under examination.

\subsubsection{Theory of Mind and Control Tasks}

ToM examined individually through a battery of $11 \mathrm{ToM}$ stories. The language of the stories was simple in order to be understood even by the younger participants. All the stories were translated in Greek and they evaluated four different aspects of advanced ToM: (a) recognition of "faux-pas", (b) understanding of second-order false belief, (c) ability to attribute complex intentional states and (d) ability to predict the emotional reactions of others. Specifically, the recognition of 'faux-pas' was tested through three stories from the Baron-Cohen, O'Riordan, Stone, Jones, \& Plaisted (1999) battery of 'faux-pas' stories. Maximum score was 6 points, that is, 2 points for each story (1 point for the correct answer to the questions following the story and 1 point for the correct justification). Second-order false belief was tested through two stories, one from Sullivan, Zaitchik, \& Tager-Flusberg (1994) and one from Hughes, Adlam, Happe, Jackson, Taylor, \& Caspi (2000). Maximum score for the two stories was 4 points, that is, 2 points for each story (the same to the above). The ability to attribute complex intentional states was evaluated with three stories from Happe's (1994) strange stories battery. The mental state stories concerned understanding of double bluff, misunderstanding, someone's effort to persuade a person and were followed by questions concerning the character's thoughts and feelings. In accordance with the scoring criteria established by O'Hare, Bremmer, Nash, Happe, \& Pettigrew (2009) and Sutton, Smith, \& Swettenham, (1999b), participants received two points for each correct response that referred to the character's mental state, one point for each response that was incomplete or did not refer to the character's mental state, and zero points for each incorrect response (Maximum score for the three stories 6 points). Finally, the ability to predict the emotional reactions of others was tested with three stories from Sutton et al. (1999b). Again, maximum score for the three stories was 6 points ( 2 points for each story: 1 point for the correct answer to the questions following the story and 1 point for the correct justification). All ToM tasks scores were added in order to have one general ToM score for every participant.

The Control tasks were three control stories from the Baron-Cohen et al. (1999) battery, which did not refer to mental states. Maximum score for the three stories was 3 points: 1 point for the correct answer in each story (that is, saying "no" in the question asking if someone in the story told something strange or non proper).

\subsubsection{Social Competence}

The Greek version (Goudas, Magotsiou, \&Hatzigeorgiades, 2009) of the Multisource Assessment of Children's Social Competence (the self-ratings) (MASCS, Junttila, et al., 2006) was used. The questionnaire consisted of four subscales, namely co-operating skills (e.g., "effectively participate in group activities"), empathy (e.g., "I am sensitive to the feelings of others", quick temper/irritability (e.g., "I have a short fuse") and disruptive behavior (e.g., "I argue and quarrel with peers"). Students were asked to report on a 4-point frequency scale ( $1=$ never to 4 $=$ very frequently). Information about its factorial validity and internal consistency will be presented in the results section.

\subsubsection{Bystanders in Bullying}

The participants completed a self-report questionnaire, the shorten version of the Participant Role Scale (Salmivalli et al., 1996; see Andreou \& Metallidou, 2004 for the Greek version). There was a short description of a bullying incident ("When some kids in your age hit other kids or make laugh of or threat or tease or offend them, some kids......") and the participants were asked to choose on a fourth point scale (1 to 4, with higher scores reflecting greater behavior matching respectively) how much each of 16 behavior descriptions fitted with their behavior in similar situations. The descriptions indicated the following participant roles: (a) assistant ( 2 items, e.g., "some kids help the bully by holding the victim", (b) reinforcer (5 items e.g., "some kids encourage the bully to continue"), (c) defender (5 items e.g., "some kids try to comfort the victim"), and (d) outsider (4 items e.g., "some kids pretend that they did not see it") (see also Sutton \& Smith, 1999). Information about its factorial validity and internal consistency will be presented in the results section.

\subsection{Procedure}

Parental permission as well as permission by the schools' administration and the Hellenic Ministry of Education 
was provided in advance. The examination took place at the end of the school year for the $3^{\text {rd }}$ and $5^{\text {th }}$ graders and at the beginning of the school year for the $4^{\text {th }}$ and $6^{\text {th }}$ graders. Participants were tested individually in ToM tasks for about one hour, in a quiet room in their schools. ToM tasks were administered in random order. In the second phase, they were tested in groups in their school classrooms with the self-reported questionnaires under the supervision of the second author. Students participated voluntarily after being informed about the purpose of the study and assured that it was an anonymous research. In terms of their demographic characteristics, they reported their gender, age, and their alphabetical order number in the classroom, for the researchers to be able to match students' self-reports with their performance on the ToM tasks. Students and parents were assured that no one else, except the researchers, would have access to their answers.

\section{Results}

\subsection{Factor Structure of the Self-Rating Questionnaires}

Principal component analysis (PCA) and subsequently confirmatory factor analysis (CFA) were performed to examine and establish the factor structure of "Multisource Assessment of Children's Social Competence" and "Roles in Bullying" questionnaires. PCA was applied using oblique rotation (Promax), which allows factors to be correlated. On the basis of the criteria: eigenvalue $>1$ (Kaiser, 1960) and Cattell's scree test (Cattell, 1966) for determining the number of factors to retain, a theoretically supported four-factor solution was revealed for the "Multisource Assessment of Children's Social Competence" questionnaire and a three-factor (instead of four-factor) solution for the "Roles in Bullying" questionnaire. Namely, assistants/reinforcers, defenders and outsiders. Items referring to assistant and reinforcing behavior were loaded on the same factor. It is noteworthy to refer here that there were only two items assessing assistant behavior and they loaded on the factor with reinforcers, probably due to conceptual resemblance. Table 1 contains eigenvalues and explained variance (\%) for the extracted components as well as Cronbach's alpha values for the corresponding subscales of the two questionnaires.

CFA was conducted using Mplus 5.0 program 5 (Muthén \& Muthén, 2007) based on maximum likelihood estimation of parameters. The two models fit the data to a satisfactory degree: For Social Competence Skills model $\chi^{2}=226.2, d f=146, p=.001, \chi^{2} / d f=1.55, \mathrm{CFI}=.94, \mathrm{TLI}=.93, \mathrm{RMSEA}=.06(90 \% \mathrm{CI}=[.04, .07]), \mathrm{SRMR}=.06$, and for Roles in Bullying model $\chi^{2}=144.5, d f=100, p=.002, \chi^{2} / d f=1.45$, CFI $=.93$, TLI $=.91$, RMSEA $=.05(90 \%$ $\mathrm{CI}=[.03, .07]), \mathrm{SRMR}=.06$. After inspection of modification indices of the latter model, we allowed a correlation between error terms of two items that load onto the same factor (item 1: "some kids report the incident to an adult (parent, teacher or another adult)" and item 2: "some kids try to stop bullying").

Table 1. Eigen values, explained variance and $\alpha$ values for self-report questionnaires

\begin{tabular}{llll}
\hline Variables & Eigenvalue & \% explained var. & Cronbach $\alpha$ \\
\hline Social Competence skills & & & .87 \\
$\quad$ Quick temper & 5.19 & 27.32 & .82 \\
$\quad$ Empathy & 3.62 & 19.05 & .79 \\
$\quad$ Disruptiveness & 1.56 & 8.22 & .69 \\
$\quad 1.23$ & 6.46 & .78 \\
Cooperation skills & & & .77 \\
Assistands/Reinforcers & 3.56 & 22.28 & .67 \\
$\quad$ Defenders & 2.64 & 16.53 & 10.94 \\
\hline
\end{tabular}

\subsection{Descriptive statistics, Correlations, and Group Differences}

Table 2 displays descriptive statistics and Table 3 correlation coefficients between the mean scores of all the variables. All the correlations were found at the expected direction. 
Table 2. Descriptive statistics

\begin{tabular}{lllll}
\hline & $\mathrm{M}$ & $\mathrm{SD}$ & Skewness & Kurtosis \\
\hline Age in months & 120.70 & 12.31 & .082 & -1.57 \\
Control Stories & 2.51 & .78 & -.164 & 2.04 \\
Theory of Mind & 13.30 & 4.26 & -.59 & -.33 \\
\hline Social Competence skills & & & .80 \\
$\quad$ Cooperation skills & 3.42 & .58 & -1.02 & -.42 \\
$\quad$ Empathy & 3.03 & .73 & -.61 & 1.25 \\
$\quad$ Disruptiveness & 1.42 & .48 & 1.25 & .03 \\
$\quad$ Quick temper & 1.89 & .78 & .88 & .31 \\
\hline Roles in Bullying & & & & -.37 \\
Assistands/Reinforcers & 1.64 & .58 & .99 & .03 \\
\multicolumn{1}{c}{ Defenders } & 2.99 & .77 & -.62 & .58 \\
$\quad$ Outsiders & 1.97 & .71 & & \\
\hline
\end{tabular}

Table 3. Bivariate correlations of the study variables

\begin{tabular}{|c|c|c|c|c|c|c|c|c|c|c|}
\hline & Age & Gender & Control & ToM & Cooper & Emp. & Disrupt & Quick t & Reinf & Defend \\
\hline Control Stories & -.08 & .03 & ---- & & & & & & & \\
\hline Theory of Mind & $.23 * *$ & .01 & .09 & ---- & & & & & & \\
\hline \multicolumn{11}{|l|}{ Social Comp. } \\
\hline Cooperation & $.19 * *$ & .04 & $.26^{* * *}$ & $.27 * * *$ & ---- & & & & & \\
\hline Empathy & .13 & $.22 * *$ & $.16^{*}$ & $.22 * *$ & $.51 * * *$ & ---- & & & & \\
\hline Disruptiveness & .09 & $-.23 * *$ & .02 & -.11 & $-.20 *$ & $-.20 *$ & ---- & & & \\
\hline Quick temper & .06 & -.08 & .01 & .06 & -.07 & -.08 & $.49 * * *$ & ---- & & \\
\hline \multicolumn{11}{|l|}{ Roles in Bullying } \\
\hline Ass/Reinforcers & -.04 & $-.23 * *$ & .03 & $-.25 * * *$ & $-.16^{*}$ & $-.28 * * *$ & $.32 * * *$ & $.25 * * *$ & ---- & \\
\hline Defenders & $.16^{*}$ & .02 & .10 & $.31 * * *$ & $.40 * * *$ & $.39 * * *$ & -.09 & .02 & -.13 & ---- \\
\hline Outsiders & -.03 & .02 & -.11 & -.13 & $-.17 *$ & -.15 & .03 & .07 & $.23 * *$ & .01 \\
\hline
\end{tabular}

Note. $0=$ boys and $1=$ girls; ${ }^{*} p \leq .05 ; * * p \leq .01 ; * * * \leq .001$.

Three positive significant correlations were found between age and performance on ToM tasks, cooperation skills and defending behavior. A series of ANOVAs with grade (group 1, $N=89: 3^{\text {rd }}$ and $4^{\text {th }}$ graders and group 2, $N=82$ : $5^{\text {th }}$ and $6^{\text {th }}$ graders) as independent variable showed that older students $(M=14.39, S D=4.00)$ performed significantly better in ToM tasks as compared to younger ones $(M=12.29, S D=4.27), F(1,169)=10.93, p=.001$, $n^{2}=.06$. Further, older students reported significantly higher cooperative skills $(M=3.54, S D=.46)$ and acting as defenders $(M=3.13, S D=.67)$ as compared to younger ones $\left(M=3.31, S D=.65, F(1,169)=7.45, p<.01, n^{2}\right.$ $=.04$ for cooperating skills and $M=2.87, S D=.84, F(1,169)=5.07, p<.05, n^{2}=.03$ for defending behavior).

In regards to correlations with gender, one positive significant correlation was found with empathy, and two negative significant correlations with disruptive behavior and acting as assistant/reinforcer in bullying. Mean level differences with gender as independent variable showed that girls reported significantly higher empathy $(M=3.17$, $S D=.68)$, as compared to boys $(M=2.85, S D=.75), F(1,169)=8.54, p<.01, n^{2}=.05$. Boys, however, reported significantly higher disruptive behavior $(M=1.54, S D=.52)$, as compared to girls $(M=1.32, S D=.43), F(1,169)$ $=9.58, p<.01, n^{2}=.05$. Moreover, boys reported that acting as assistnants/reinforcers is significantly more fitted to their behavior $(M=1.78, S D=.64)$, as compared to girls $(M=1.52, S D=.49), F(1,169)=9.53, p<.01, n^{2}=.05$.

Performance on Control stories correlated significantly only with the two pro-social factors (cooperation skills and 
empathy), while performance on ToM tasks correlated significantly not only with the above prosocial competence factors (positively) but with participant roles as well (positively with defenders and negatively with assistants/reinforcers).

\subsection{Direct and Indirect Effects on Self-Ratings for Bystanding Behavior}

Path analysis was applied on the data using Mplus 5.0 (Muthén \& Muthén, 2007) with ML method. Direct paths were drawn from ToM to each social competence factor and each participant role. Further, direct paths were drawn from each social competence factor to each participant role. Indirect paths were also tested. The factor of quick temper/irritability was removed from the model as no significant path to and from that factor was significant. It was found to correlated significantly only with the assistant/reinforcer role (see Table 3), but given its strong positive correlation with the disruptive behavior factor $(r=.49)$, it was not found as significant predictor of the above participant role.

The hypothesized model had a good fit to the data. The indices of the model were: $\chi 2(12)=12.82, p=.38$, CFI $=.995, \mathrm{RMSEA}=.02, \mathrm{SRMR}=.04$. All the direct paths that are presented in Figure 1 are significant. The effect of age was found significant only in one case. It explained part of the variance of performance on ToM tasks, as expected. Performance on ToM tasks affected directly self-ratings for cooperation skills and empathy and two participant roles, self-ratings for defending behavior (positively) and for assistant/reinforcing behavior (negatively). Social competence factors predicted, in turn, directly the three participant roles. Cooperation skills predicted positively defending behavior and negatively the outsider behavior. Empathy predicted positively defending behavior and negatively the assistant/reinforcer behavior. Finally, the anti-social factor of disruptive behavior predicted positively only the assistant/reinforcer behavior.

In addition to the direct paths, three indirect effects were found to be significant: defending behavior explained indirectly by ToM via cooperation skills (indirect effect estimate $=.010$ ) and empathy (indirect effect estimate $=.009$ ). Also, outsider behavior explained indirectly by ToM via cooperation skills (indirect effect estimate $=$ -.008). The significance of indirect effects was tested using $95 \%$ bias-corrected bootstrap confidence interval that is considered the most appropriate method for testing indirect effects (Fritz \& MacKinnon, 2007; MacKinnon et al., 2004).

Multiple group analysis was used in order to examine the moderating role of gender in the relationships between ToM and bystanding behavior described by the path model. For this purpose, the unconstrained model was estimated allowing the direct paths to differ across boys and girls. Then, the constrained model was generated, in which the direct path estimates in the two groups are constrained to be equal. Finally, the chi-square difference test was calculated between the unconstrained and constrained models in order to reveal whether the moderating role of gender was significant. The unconstrained model fitted the data for both groups very well: $\mathrm{CFI}=1.00, \mathrm{TLI}=$ 1.04, RMSEA $=.00(90 \% \mathrm{CI}=[.00, .07])$. The constrained model also fitted the data for both groups very well: $\mathrm{CFI}=1.00, \mathrm{TLI}=1.06, \mathrm{RMSEA}=.00(90 \% \mathrm{CI}=[.00, .06])$. A non-significant difference between the constrained and unconstrained models was found showing that both groups have the same path coefficients: $\Delta \chi^{2}(d f=10)=7.55$, $p>$.05.Thus, it can be concluded that the path model was not moderated by gender. 


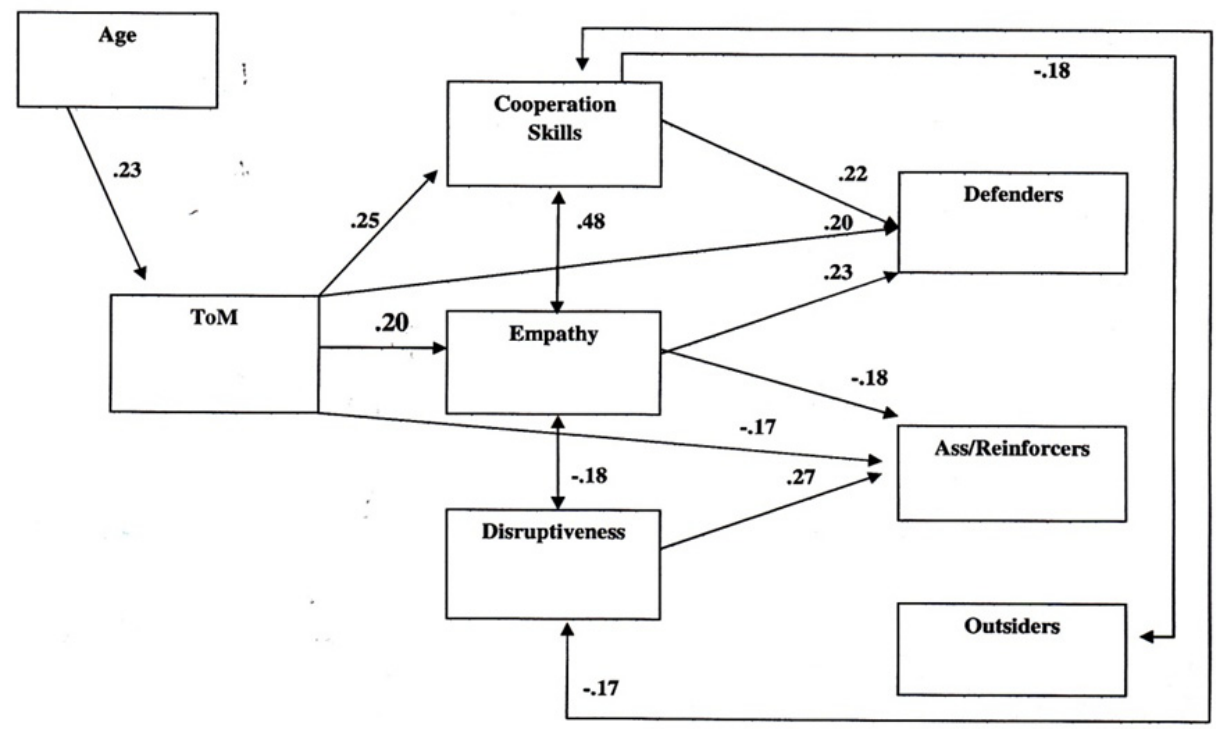

Figure 1. The standardized path coefficients for direct effects

Note. All path coefficients are significant.

\section{Discussion}

It is well acknowledged that bullying is a group-based phenomenon and bystanders "matter", especially for prevention programs to be effective (Salmivali et al., 2011). Research, however, on the motivational and socio-cognitive profile of bystanders in school bullying is still limited, especially for the assistants, reinforcers and outsiders (Forsberg et al., 2014; Pronk et al., 2013). The present study contributes to the bullying literature by providing empirical evidence for the network of direct and indirect relations between different participant roles and socio-cognitive factors in elementary school years. Specifically, it examines the contribution of Theory of Mind (ToM) to elementary students' self-ratings for the adoption of different participant roles in bullying incidents. Direct and indirect effects (via social competence ratings) of ToM on children's self-ratings for acting as bystanders in bullying incidents were investigated. The results of the present study confirmed most of our hypotheses. Path analysis indicated direct and indirect significant effects of ToM on bystanding behavior. Further, the contribution of ToM and social competence factors were differentiated according to the specific participant role.

\subsection{ToM and Social Competence Skills Effects on Defending Behavior}

Defending behavior positively predicted by performance on ToM tasks (see Hypothesis 1a), supporting previous evidence (see also Caravita et al., 2010; Gini, 2006). Further, it was positively and directly predicted, as expected, by affective empathy (Hypothesis 1b) (see also van der Ploeg et al., 2017), and cooperative skills (Hypothesis 1c). Further, ToM directly affected the two pro-social factors (cooperation skills and affective empathy) and indirectly, via these direct effects, the defending behavior. In general, the present results confirmed previous evidence describing the defenders as socially competent children in elementary years, with high levels of affective empathy (see Mitsopoulou \& Giovazolias, 2015. van der Ploeg et al., 2017), effective cooperation skills (as evidenced in the present study), and high abilities to "read others' mind" (Gini, 2006; Smith, 2017). Also, the present results extends previous literature by indicating that high mentalizing abilities can affect defending behavior not only directly but indirectly as well, via their positive effect on affective empathy and cooperative skills. It can be used, then, "for cooperating and prosocial purposes" (Smith, 2017).

\subsection{ToM and Social Competence Skills Effects on Assisting/Reinforcing Behavior}

In regards to the contribution of ToM and social competence skills in the formation of assisting and reinforcing behavior, only direct significant paths were found from both factors. ToM and affective empathy negatively predicted the respective self-ratings, while disruptive behavior had a positive effect. The present results extend Crick \& Dodge's (1994) claim for a 'social skills deficit' of aggressive children. They indicate that not only aggressive children who act as bullies have low abilities in ToM, but those children that follow the bully as well, 
either by assisting or by reinforcing the bully. Given the limited evidence and the fact that the existing evidence found weak or non-significant associations between ToM and assistants and reinforcers (see Smith, 2017), further research is needed. Further, it is noteworthy that at a correlational level assistants and reinforcers described themselves negatively as regards their social competence skills, supporting previous evidence indicating that not only bullying but following behavior as well is associated with low social competence (Camodeca et al., 2015). The more assisting/reinforcing behavior they report the more they describe themselves as having lower prosocial skills (affective empathy and cooperative skills) and higher antisocial skills (disruptive behavior and quick temper in their social interactions). It seems that they are a group "at risk" of stop being followers and taking more active part in bullying incidents.

\subsection{ToM and Social Competence Skills Effects on Outsiding Behavior}

One of the most interesting findings was that ratings for uninvolved behavior predicted negatively only by cooperation skills and indirectly by ToM, via its direct effect on cooperation skills. Previous evidence has also indicated low levels of social self-efficacy in outsiders' behavior (Gini et al., 2008) as well as low social status and popularity among their peers (Caravita et al., 2009, 2010). There is a paradox, though, concerning the popularity of bullies and outsiders. In general, the evidence suggests that the aggressive children are not popular and they are likely to acquire low status in the peer group (Caravita et al., 2009). It is noteworthy, however, that, while bullies are more disliked than uninvolved group of children in bullying situations, they are at the same time less socially isolated than the uninvolved children (Veenstra, et al., 2005). Children with high antisocial behavior (e.g., aggressive, hostile) were found to be among the most popular (tough boys), socially connected and popular children in elementary years (e.g., Rodkin et al., 2000). The results of the present study provide a possible explanation that may involve the outsiders' low cooperation skills, according to their self-ratings. The results support a kind of "abstention" from social interactions with peers. It is noteworthy that no significant correlations were found with most of the examined variables. It may stay aside because of their lack in cooperation skills or because of a "deficit" in reading others' motives, feelings and intentions and this, in turns, keeping them isolated and away not only from conflicts but from close relations with peers as well. Future research should focus on the socio-cognitive profile of this group of students in order to delimit their strengths and weaknesses. It seems that they can be also an "at risk" group, given the positive significant correlation that was found in the present study between ratings for uninvolved behavior and assisting/reinforcing behavior.

\subsection{The Moderating Effect of Gender}

Multiple group path analysis showed no significant effect of gender as moderator in the relationships between ToM, social competence, and bystanding behavior described by the path model. The present results indicate that the network of direct and indirect predictive paths is the same in both genders, even though there were found significant gender differences of medium effect size $\left(n^{2}=.05\right)$ at the mean level. Specifically, girls reported significantly higher affective empathy and lower disruptive behavior as compared to boys, which is a consistent evidence (see Caravita et al., 2009, 2010). Moreover, boys reported acting as assistnants/reinforcers significantly more fitted to their behavior in bullying incidents as compared to girls, which again has been consistently found in previous research (e.g., Anderou \& Metallidou, 2004; Salmivalli et al., 1996). No significant gender differences were found, though, in ToM. This is in line with previous evidence for non significant interactions between ToM, bystanding behavior and gender (see review from Smith, 2017). The present results stress the need to focus on the socio-cognitive individual predictors of bystanding behavior that could enhance the use of prosocial resources in bullying incidents or prevent children from using these resources, irrespective of their more stable individual differences factors, like gender. Given the small sample size, future studies, nevertheless, should examine the systematic nature of the present findings and the possibility of significant gender effects as a function of different types of bullying witness by boys and girls (e.g., physical or verbal).

\subsection{Limitations and Future Research}

One main limitation of the present study, apart from the correlational, cross sectional design, is the use of self-ratings for measuring social competence skills and participant roles. Most of the previous studies used nomination rates. Given, however, the recent evidence for 'moderate' stability in the roles children adopt over time and their possible need to adopt multiple participant roles at the same time, depending on personal and situational factors (see Maunder \& Crafter, 2018), self-ratings could be useful for uncovering children's perception of their behavior in various bullying incidents. Even though the self-report questionnaire that has been used in the present study is a well-fitted instrument according to its psychometric properties, future attempts should involve social desirability controls in self-reported measures in order to minimize the above limitation. Further, future studies should be multi-methodological and use self-ratings, nominations, behavioral measures, as well as measures from 
multiple raters (e.g., teachers, parents, peers), in order to give a more definite answer whether the network of direct and indirect effects described in the present study is systematic or not. Moreover, situational factors (e.g., the number of bystanders during an incident) may be important mediators in the relation between ToM and bystanding behavior. In addition, the present results in regards to the role of ToM as predictor may be due to the type of ToM tasks and the participants' age (see Smith, 2017). Future studies with younger and older children or, even better, longitudinal studies and tasks that involve different aspects of ToM (cognitive vs perceptual or cognitive vsaffective, or verbal vs visual tasks) could set more light on the network of the examined effects and the dynamics of the effects within each school year. Finally, size and specific characteristics of the sample limit the generalizability of the present findings.

\subsection{Conclusion and Educational Applications}

One of the main conclusions of the present study is that ToM is a significant predictor of participant roles in bullying. It is worth mentioning that only performance on the ToM tasks and not on the control ones proved as a significant predictor. Further, ToM can be used "for cooperating and prosocial purposes" (Smith, 2017, p. 5), supporting, thus, the significance of including training in mentalizing abilities in bullying prevention programs. High mentalizing abilities could empower children's procosial skills. Moreover, a significant percentage of children (almost 24-30\%) have been found not to take side or to withdraw from bullying incidents. It is important to boost, according to the present data, mainly their cooperative skills in an attempt to feel accepted by their peers and efficient to react in bullying incidents. Future prevention programs should focus on these children as well, with the aim to change their attitude and adopt that of the defenders'. The positive correlation found between outsiders and assistants/reinforcers is an indication that they may be at risk. It seems that they are also a group "at risk" of stop being followers and taking more active part in bullying incidents. Future interventions should strengthen their mentalizing skills and reduce their disruptive behavior. One way is to disconnecting it from high popularity gains, especially in elementary years. Finally, given that bullying occurs within a social context, it is more than obvious that interventions should focus on individual and contextual predictors in order to be effective, even though contextual predictors were not examined in the present study. Namely, education policy makers should include in the curriculum cooperative learning activities and projects that reinforce cooperation and joint work in various school subjects. This could help students to appreciate their classmates strengths and their contribution to team work and to build social networks that are based on mutual understanding and respect (e.g., exchanging ideas and accepting different views of the world). School administration and teachers should, in turn, cultivate a cooperative climate for learning and reinforce social activities as a bullying mitigation strategy. This could allow teachers to identify easier children who are socially and/or academically isolated and could be "at risk" for experiencing victimization. In such cases, children with high mentalizing, cooperative and empathy skills could help teachers by comforting and supporting those children.

\section{Acknowledgements}

We would like to express our deepest thanks to Dr. Jon Sutton who sent us the stories for testing the children's ability to predict the emotional reactions of others, and to Dr. Plousia Misailidi for her assistance to chose the appropriate ToM tasks.

\section{References}

Andreou, E., \& Metallidou, P. (2004).The relationship of academic and social cognition to behavior in bullying situations among Greek primary school children. Educational Psychology, 24, 27-41. https://doi.org/10.1080/0144341032000146421

Bjorkqvist, K., Osterman, K., \& Kaukiainen, A. (2000). Social intelligence - Empathy = Aggression? Aggression and Violent Behavior, 5, 191-200. https://doi.org/10.1016/S1359-1789(98)00029-9

Banerjee, R., Watling, D., \& Caputi, M. (2011). Peer relations and the understanding of faux pas: Longitudinal

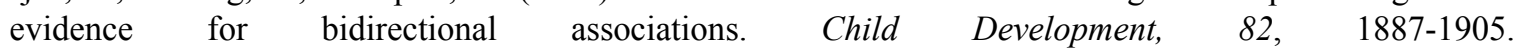
https://doi.org/10.1111/j.1467-8624.2011.01669.x

Barlow, A., Qualter, P., \& Styllianou, M. (2010).Relationships between Machiavellianism, emotional intelligence and theory of mind in children. Personality and Individual Differences, 48, 78-82. https://doi.org/10.1016/j.paid.2009.08.021

Baron-Cohen, S., O'Riordan, M., Stone, V., Jones, R., \& Plaisted, K. (1999). Recognition of faux pas by normally developing children with Asperger syndrome or high functioning autism. Journal of Autism and Developmental Disorders, 29, 407-418. https://doi.org/10.1023/A:1023035012436 
Baxevani, M., \&Metallidou, P. (2015). Primary school children's Theory of Mind as predictor of self-reported bullying and victimization: The moderating role of empathy and social competence [in Greek]. In M. Kosmides, D. Xanthopoulou, E. Aretouli, \& E. Gonida (Eds.), Scientific Annals of School of Psychology, A.U.Th. (Vol. XI, pp. 84-117).

Camodeca, M., Caravita, S. C. S., \& Coppola, G. (2015). Bullying in preschool: The associations between participant roles, social competence, and social preference.Aggressive Behavior, 41, 310-321. https://doi.org/10.1002/ab.21541

Caputi, M., Lecce, S., Pagnin, A., \& Banerjee, R. (2012). Longitudinal effects of Theory of Mind on later peer relations: The role of Prosocial Behavior. Developmental Psychology, 48, 257-270. https://doi.org/10.1037/a0025402

Caravita, S. C. S., Di Blasio, P., \& Salmivalli, C. (2009). Unique and interactive effects of empathy and social status on involvement in bullying. Social Development, 18, 140-163. https://doi.org/10.1111/j.1467-9507.2008.00465.x

Caravita, S. C. S., Di Blasio, P., \& Salmivalli, C. (2010). Early adolescent's participation in bullying: Is ToM involved? The Journal of Early Adolescence, 30, 138-170. https://doi.org/10.1177/0272431609342983

Crick, N. R., \& Dodge, K. A. (1994). A review and reformulation of social information-processing mechanisms in children's social adjustment.Psychological Bulletin, 115, 74-101. https://doi.org/10.1037/0033-2909.115.1.74

Cook, C. R., Williams, K. R., Guerra, N. G., Kim, T. E., \& Sadek, S. (2010). Predictors of bullying and victimization in childhood and adolescence: A meta-analytic investigation. School Psychology Quarterly, 25, 65-83. https://doi.org/10.1037/a0020149

Devy, R. T., White, N., Ensor, R., \& Hughes, C. (2016). Theory of mind in middle childhood: Longitudinal associations with executive function and social competence. Developmental Psychology, 52, 758-771. https://doi.org/10.1037/dev0000105

Forsberg, C., Thornberg, R., \& Samuelsson, M. (2014). Bystanders to bullying: Fourth to seventh grade students' perspectives on their reactions. Research Papers in Education, 29, 557-576. https://doi.org/10.1080/02671522.2013.878375

Fritz, M. S., \& MacKinnon, D. P. (2007). Required sample size to detect the mediated effect. Psychological Science, 18, 233-239. https://doi.org/10.1111/j.1467-9280.2007.01882.x

Gini, G. (2006). Social cognition and moral cognition in bullying: What's wrong? Aggressive Behavior, 32, 528-539. https://doi.org/10.1002/ab.20153

Gini, G., Albiero, P., Benelli, B., \& Altoe, G. (2008). Determinants of adolescents' active defending and passive bystanding behavior in bullying. Journal of Adolescence, 31, 93-105. https://doi.org/10.1016/j.adolescence.2007.05.002

Goudas, M., Magotsiou, E., \& Hatzigeorgiadis, A. (2009). Factor invariance of two forms of the "Multisource Assessment of Children's Social Competence Scale" [in Greek]. In A. Mprouzos, P. Misailidi, \& A. Efklides (Eds.), Scientific Annals of the Psychological Society of Northern Greece (Vol. 7, pp. 96-114). Athens: Ellinika Grammata.

Happe, F. (1994). An advanced test of theory of mind: Understanding of story characters' thoughts and feelings by able autistic, mentally handicapped, and normal children and adults. Journal of Autism and Developmental Disorders, 24, 129-154.https://doi.org/10.1007/BF02172093

Hughes, C., Adlam, A., Happe, F., Jackson, J., Taylor, A., \& Caspi, A. (2000). Good test-retest reliability for standard and advanced false-belief tasks across a wide range of abilities. Journal of Child Psychology and Psychiatry, 41, 483-490. https://doi.org/10.1111/1469-7610.00633

Hughes, C., \& Leekam, S. (2004). What are the links between theory of mind and social relations? Review, reflections and new directions for studies of typical and atypical development. Social Development, 13, 590-619. https://doi.org/10.1111/j.1467-9507.2004.00285.x

Jolliffe, D., \& Farrington, D. P. (2011). Is low empathy related to bullying after controlling for individual and social background variables? Journal of Adolescence, 34, 59-71. https://doi.org/10.1016/j.adolescence.2010.02.001

Junttila, N., Voeten, M., Kaukiainen, A., \&Vauras, M. (2006). Multisource assessment of children's social 
competence. Educational and Psychological Measurement, 674-895. https://doi.org/10.1177/0013164405285546

MacKinnon, D. P., Lockwood, C. M., \& Williams, J. (2004). Confidence limits for the indirect effect: Distribution of the product and resampling methods. Multivariate Behavioral Research, 39, 99-128. https://doi.org/10.1207/s15327906mbr3901_4

Maunder, R. E., \& Crafter, S. (2018). School bullying from a sociocultural perspective. Aggression and Violent Behavior, 38, 13-20. https://doi.org/10.1016/j.avb.2017.10.010

Miller, S. A. (2009). Children's understanding of second-order mental states. Psychological Bulletin, 135, 749-773. https://doi.org/10.1037/a0016854

Mitsopoulou, E., \& Giovazolias, T. (2015). Personality traits, empathy and bullying behavior: A meta-analytic approach. Aggression and Violent Behavior, 21, 61-72. https://doi.org/10.1016/j.avb.2015.01.007

Muthén, L. K., \& Muthén, B. (1998-2007). Mplus User's Guide. Los Angeles, CA: Muthén\&Muthén.

O’Hare, A. E., Bremmer, L., Nash, M., Happe, F., \& Pettigrew, L. M. (2009). A clinical assessment tool for advanced theory of mind performance in 5 to 12 year olds. Journal of Autism and Developmental Disorders, 39, 916-928. https://doi.org/10.1007/s10803-009-0699-2

Olweus, D. (1993). Bullying at school: What we know and what we can do. Oxford: Blackwell.

Pozzoli, T., Gini, G., \&Thornberg, R. (2016). Bullying and defending behavior: The role of explicit and implicit moral cognition. Journal of School Psychology, 59, 67-81. https://doi.org/10.1016/j.jsp.2016.09.005

Pronk, J., Goossens, F. A., Olthof, T., De Mey, L., \& Willemen, A. M. (2013). Children's intervention strategies in situations of victimization by bullying: Social cognitions of outsiders versus defenders. Journal of School Psychology, 51, 669-682. https://doi.org/10.1016/j.jsp.2013.09.002

Renouf. A., Brendgen, M., Parent, S., Vitaro, F., Zelazo, P. D., Boivin, M., ... Seguin, J. R. (2010). Relations between theory of mind and indirect and physical aggression in kindergarten: Evidence of the moderating role of prosocial behaviors. Social Development, 19, 535-555. https://doi.org/10.1111/j.1467-9507.2010.00586.x

Rodkin, P. C., Farmer, T. W., Pearl, R., \& Van Acker, R. (2000). Heterogeneity of popular boys: Antisocial and prosocial configurations. Developmental Psychology, 36, 14-24. https://doi.org/10.1037/0012-1649.36.1.14

Salmivalli, C. (2010). Bullying and the peer group: A review. Aggression and Violent behavior, 15, $112-120$. https://doi.org/10.1016/j.avb.2009.08.007

Salmivalli, C., Lagerspetz, K., Bjorkvist, K., Osterman, K., \& Kaukiainen, A. (1996). Bullying as a group process: Participant roles and their relations to social status within the group. Aggressive Behavior, 22, 1-15. https://doi.org/10.1002/(SICI)1098-2337(1996)22:1<1::AID-AB1>3.0.CO;2-T

Salmivalli, C., Voeten, M., \& Poskiparta, E. (2011). Bystanders matter: Associations between reinforcing, defending, and the frequency of bullying behavior in classrooms. Journal of Clinical Child \& Adolescent Psychology, 40, 668-676. https://doi.org/10.1080/15374416.2011.597090

Shakoor, S., Jaffee, S. R., Bowes, L., Ouellet-Morin, I., Andreou, P., Happe, F., ...Arseneault, L. (2012). A prospective longitudinal study of children's theory of mind and adolescent involvement in bullying. Journal of Child Psychology and Psychiatry, 53, 254-261. https://doi.org/10.1111/j.1469-7610.2011.02488.x

Smith, P. K. (2017). Bullying and Theory of Mind: A Review. Current Psychiatry Reviews, 13, 90-95. https://doi.org/10.2174/1573400513666170502123214

Stavrinides, P., Georgiou, S., \& Theofanous, V. (2010). Bullying and empathy: A short-term longitudinal investigation. Educational Psychology: An International Journal of Experimental Educational Psychology, 30, 793-802. https://doi.org/10.1080/01443410.2010.506004

Sullivan, K., Zaitchik, D., \& Tager-Flusberg, H. (1994). Preschoolers can attribute second-order beliefs. Developmental Psychology, 30, 395-402. https://doi.org/10.1037/0012-1649.30.3.395

Sutton, J., \& Smith, P. K. (1999). Bullying as a social process: An adaptation of the Participant Role Scale $\begin{array}{llrl}\text { approach. } \quad \text { Aggressive } & \text { Behavior, } & \text { 97-111. }\end{array}$ https://doi.org/10.1002/(SICI)1098-2337(1999)25:2<97::AID-AB3>3.0.CO;2-7

Sutton, J., Smith, P. K., \& Swettenham, J. (1999). Bullying and 'Theory of Mind': A critique of the 'social skills deficit' view of anti-social behaviour. Social Development, 8, 117-127. 
https://doi.org/10.1111/1467-9507.00083

Sutton, J., Smith, P. K., \& Swettenham, J. (1999b). Social cognition and bullying: Social inadequacy or skilled manipulation. British Journal of Developmental Psychology, 17, 435-450. https://doi.org/10.1348/026151099165384

Van der Ploeg, R., Kretschmer, T., Salmivali, C., \&Veenstra, R. (2017). Defending victims: What does it make to intervene in bullying and how is it rewarded by peers? Journal of School Psychology, 65, 1-10. https://doi.org/10.1016/j.jsp.2017.06.002

Van Noorden, T.H.J., Haselager, G.J.T., Cillessen, A.H.N., \& Bukowski, W.M. (2015). Empathy and involvement in bullying in children and adolescents: A systematic review. Journal of Youth and Adolescence, 44, 637-657. https://doi.org/10.1007/s10964-014-0135-6

Veenstra, R., Lindenberg, S., Oldehinkel, A. J., De Winter, A. F., Verhulst, F. C., \&Ormel, J. (2005). Bullying and Victimization in elementary schools: A comparison of bullies, victims, bully/victims, and uninvolved preadolescents. Developmental Psychology, 41, 672-682. https://doi.org/10.1037/0012-1649.41.4.672

Warden, D., \& Mackinnon, S. (2003). Prosocial children, bullies and victims: An investigation of their sociometric status, empathy and social problems-solving strategies. British Journal of Developmental Psychology, 21, 367-385. https://doi.org/10.1348/026151003322277757

Wellman, H., M., Cross, D., \& Watson, J. (2001). Meta-analysis of theory of mind development: The truth about false belief. Child Development, 72, 655-684.https://doi.org/10.1111/1467-8624.00304

\section{Copyrights}

Copyright for this article is retained by the author(s), with first publication rights granted to the journal.

This is an open-access article distributed under the terms and conditions of the Creative Commons Attribution license (http://creativecommons.org/licenses/by/4.0/). 